\title{
Insights Into a Watermelon Virome Contribute to Monitoring Distribution of Whitefly-Borne Viruses
}

\author{
Neta Luria, ${ }^{1}$ Elisheva Smith, ${ }^{1}$ Noa Sela, ${ }^{1}$ Amnon Koren, ${ }^{2}$ Oded Lachman, ${ }^{1}$ and Aviv Dombrovsky ${ }^{1, \dagger}$ \\ ${ }^{1}$ Department of Plant Pathology and Weed Research, Agricultural Research Organization, The Volcani Center, 68 \\ HaMaccabim Road, P.O. Box 15159 Rishon LeZion 7505101, Israel; and ${ }^{2}$ Histhil Nurseries, Moshav Nehalim, Israel \\ Accepted for publication 15 January 2019.
}

\section{ABSTRACT}

The composition of a plant virome may represent spatiotemporal patterns of plant virus abundance. Using next generation sequencing, we investigated the viromes of watermelon fruits grown in two adjacent open fields located in Eastern Israel: Kalia and Mitzpe-Shalem. The two viromes were comprised of distinct virus species and genera. Studying spatial and temporal effects on virus occurrence, we detected the crinivirus Cucurbit yellow stunting disorder virus in Kalia and not in Mitzpe-Shalem, irrespective of collection time. A spatial effect was also observed regarding the occurrence of the begomovirus Watermelon chlorotic stunt virus, which was not detected in watermelons from Kalia, but rather in watermelon fruit in Northern Israel in 2018. A temporal effect was observed on the appearance of the ipomovirus Cucumber vein yellowing virus, which was detected in watermelons from Kalia in 2017 and was absent in the 2016 virome analysis. Importantly, regardless of temporal and spatial effects, the crinivirus Cucurbit chlorotic yellows virus, which was new to Israeli landscape, was detected in all the tested watermelon plants. These changes in viral abundance were associated with an early whitefly (Bemisia tabaci) occurrence, which might be the cause for the severe disease spread in watermelons.

Keywords: Bemisia tabaci, Cucurbit chlorotic yellows virus, spatial, temporal.
Watermelon (Citrullus lanatus Thunb.) crop production is important to the Israeli economy. This crop is grown throughout the year. At the beginning of the warm weather growing season, watermelon plants are grown mostly in open fields and are therefore susceptible to infections by insect-transmitted viruses. Various viruses that infect watermelons in Israel have been described, such as Squash leaf curl virus (SLCV), which mildly affects the plants, Watermelon chlorotic stunt virus (WmCSV) (Abudy et al. 2010) and Squash vein yellowing virus (SqVYV) (Adkins et al. 2007; Reingold et al. 2016), which both cause severe disease symptoms. In the recent years, growers, inspectors, and retail chains in Israel reported an increase in unmarketable watermelon fruits showing unfamiliar severe disease symptoms. It seemed possible that a new combination of cucurbit-infecting viruses caused the severe disease.

${ }^{\dagger}$ Corresponding author: A. Dombrovsky; aviv@volcani.agri.gov.il

Funding: This research was supported by grants from ARIMNet2, the Israeli Chief Scientist, Ministry of Agriculture (grant 20-10-0045) (Coordination of Agricultural Research in the Mediterranean, emerging plant viruses in the Mediterranean Basin) and from the Watermelon growers fund (grant 132194518).

The author(s) declare no conflict of interest.

(C) 2019 The American Phytopathological Society
Virus-host interactions often affect interrelationships between coinfecting viruses (Kamitani et al. 2016). Although modulation of viral pathogenesis may be beneficial for the viruses as well as for the plants (Pagán et al. 2014), severe symptoms are often observed upon multiple infections. Severe symptoms might occur by cooperativity between highly pathogenic viruses and viruses that cause asymptomatic infections (Syller 2012). Establishment of cooperativity between viruses may be through a viral antagonistic activity toward plant defense mechanisms (Incarbone and Dunoyer 2013). A prominent plant defense mechanism that is induced during viral infection is RNA silencing. This mechanism can be exploited to detect new viruses. The dsRNA that occurs in the plant cells during viral replication is processed by Dicer-like proteins into small interfering RNA (siRNA) molecules, which target viral RNA for degradation (Baulcombe 1999; Valli et al. 2011). Small RNA (sRNA) preparations from infected plants may therefore be analyzed for viruses populating the host (Roossinck et al. 2015; Santala and Valkonen 2018). However, viruses that do not induce RNA silencing or those that counteract the plant defense mechanism by activating suppressor genes might not be recovered in preparations of sRNA. Therefore total RNA preparations may be required for recovering new viruses (Pecman et al. 2017; Roossinck et al. 2015).

Severe disease symptoms may also occur due to an overlapping spread of vector-transmitted viruses, which might be caused by an 
early appearance of insect vectors due to climate change. The whitefly Bemisia tabaci is an insect vector that is considered a worldwide pest (Hadjistylli et al. 2016). In the Mediterranean region, there are primarily two biotypes: $\mathrm{B}$ and $\mathrm{Q}$, which are also known, respectively, as Middle Eastern Asia Minor 1 (MEAM1) and Mediterranean (MED) (Ghanim 2014; Jones 2003; NavasCastillo et al. 2011). Whitefly-transmitted plant viruses belong to several families and genera. The genus Begomovirus consists the majority of the viruses transmitted by whiteflies (Jones 2003). These viruses are transmitted in a persistent circulative manner (Pakkianathan et al. 2015; Rosen et al. 2015). Viruses belonging to the genus Crinivirus (Abrahamian and Abou-Jawdah 2014; Lapidot et al. 2014) and genus Ipomovirus are also transmitted by whiteflies but in a semipersistent manner (Adkins et al. 2007; Dombrovsky et al. 2014; Gilbertson et al. 2015; Harpaz and Cohen 1965; Lecoq et al. 2007; Reingold et al. 2016). Interestingly, the crinivirus Cucurbit chlorotic yellows virus (CCYV), which has a bipartite positive sense RNA genome, is preferentially transmitted by B. tabaci MED biotype and a mutualistic relationship occurs between the vector and the virus ( $\mathrm{Lu}$ et al. 2017). The aim of the current study was to use next generation sequencing (NGS) technology to identify the composition of the viromes of watermelon fruits showing severe pathogenicity collected from open fields in Northern coastal area of the Dead Sea in Eastern Israel. Finding new unknown viruses in a plant virome may be crucial for the analysis of causal relationships between viruses and their symptomatic infection. CCYV, which was new to the Israeli landscape, was identified among the discovered viruses. The newly obtained viromes served for diagnosis of a range of field-collected samples, analyzing spatial and temporal effects on virus occurrence.

TABLE 1

List of primers used for diagnostics and validation of the infected watermelons

\begin{tabular}{|c|c|c|}
\hline Primer name ${ }^{a}$ & Sequence $\left(5^{\prime}-3^{\prime}\right)$ & Virus \\
\hline$S q-F-1-I L^{b}$ & ACATGAAAATTCAACACAACGAC & SqVYV-IL \\
\hline Sq-R-435-IL ${ }^{b}$ & CACCGCATTCACAGTATGTCT & SqVYV-IL \\
\hline $\begin{array}{l}\text { CCYV-F-7017- } \\
\text { RdRPC }^{c}\end{array}$ & AGGACTGGTTCACCGAACAC & $\begin{array}{l}\text { CCYV } \\
\text { (RNA 1) }\end{array}$ \\
\hline $\begin{array}{l}\text { CCYV-R-7550- } \\
\text { RdRP }^{c}\end{array}$ & TCCCACAATTTCCTGAAAGC & $\begin{array}{l}\text { CCYV } \\
\text { (RNA 1) }\end{array}$ \\
\hline $\begin{array}{l}\text { CCYV-F-6215- } \\
\text { CPM }^{\mathrm{C}}\end{array}$ & GGTGAGGACTTCCAACCAAA & $\begin{array}{l}\text { CCYV } \\
\text { (RNA 2) }\end{array}$ \\
\hline $\begin{array}{l}\text { CCYV-R-6730- } \\
\text { CPM }^{\text {C }}\end{array}$ & TACAAAACGACACCCCCATT & $\begin{array}{l}\text { CCYV } \\
\text { (RNA 2) }\end{array}$ \\
\hline CVYV-F-CP & GCTTCTGGTTCTCAAGTGGA & CVYV \\
\hline CVYV-R-CP ${ }^{d}$ & GATGCATCAGTTGTCAGATG & CVYV \\
\hline CYS-F-HSP-IN & TCAGCAGTTATGTTAACGGTGTT & CYSDV \\
\hline CYS-R-HSP-IN ${ }^{e}$ & TGCTGCAGATGGTTCGTTTA & CYSDV \\
\hline SL-F-CP & GGCAAGATATGGATGGACG & SLCV \\
\hline SL-R-CP & CAGACTTAACACAAAAGCGC & SLCV \\
\hline WM-F-Rep ${ }^{e}$ & CCGCACTTTAGATCAACGCG & WmCSV \\
\hline WM-R-Rep ${ }^{\mathrm{e}}$ & ATGAGGCCTCCCCGCTTTAG & WmCSV \\
\hline \multicolumn{3}{|c|}{$\begin{array}{l}\text { a SqVYV, Squash vein yellowing virus; CCYV, Cucurbit chlorotic } \\
\text { yellows virus; CVYV, Cucumber vein yellowing virus; CYSDV, } \\
\text { Cucurbit yellow stunting disorder virus; SLCV, Squash leaf curl virus; } \\
\text { and WmCSV, Watermelon chlorotic stunt virus. } \\
\text { b Reingold et al. } 2016 . \\
\text { c Current work. } \\
\text { d Lecoq et al. } 2007 . \\
\text { e Y. Antignus, O. Lachman, and M. Pearlsman, unpublished data. }\end{array}$} \\
\hline
\end{tabular}

\section{MATERIALS AND METHODS}

Sample collections. Symptomatic watermelon fruits were collected in 2016 and 2017 from open fields in Kalia and MitzpeShalem, respectively, which are located on the Northern coast of the Dead Sea in Eastern Israel. Fruit samples (flesh, rind, and skin) from four watermelon plants from each location were pooled and subjected to RNA extraction and NGS analysis, to establish the species comprising the viromes. In addition, two batches of four watermelon fruits that were collected from Kalia in 2016 were sampled (flesh, rind, and skin) and from each batch RNA was extracted (by a different method) for NGS analysis. A temporal effect on the occurrence of viruses infecting watermelons was studied by collecting 30 and 24 symptomatic watermelon fruits from Kalia in 2017 and 2018, respectively. A spatial effect on the occurrence of the investigated viruses was studied by collecting samples from Northern Israel: 39 symptomatic watermelon fruits from Eden farm in 2017, and 10 symptomatic leaves from Ein Harod in 2018. In addition, in 2018, four selected symptomatic watermelon fruits and leaves were collected from the Arava Valley in Southern Israel. A net effect on the distribution of viruses infecting the watermelons was studied in Kalia in 2018 by placing an anti-insect 50 mesh net, $100 \mathrm{~m}$ long and $6 \mathrm{~m}$ wide, in the middle of the open field. Twenty-four watermelon fruits were analyzed for virus infection. Fruit (pooled flesh, rind, and skin) and leaf samples for the temporal, spatial, and net effect studies were subjected to PCR and RT-PCR analyses individually.

RNA extractions for NGS analyses. Three methods of RNA extraction were employed on symptomatic watermelon fruits collected from Kalia in 2016: (i) Fruit samples (flesh, rind, and skin) from four watermelon plants were combined and subjected to total RNA preparation (GeneElute Mammalian Total RNA Miniprep kit, Sigma-Aldrich). (ii) Fruit samples (flesh, rind, and skin) from four watermelon plants were pooled and subjected to small RNA preparation using mirVana miRNA Isolation Kit (Invitrogen, Carlsbad, CA). (iii) Fruit samples (flesh, rind, and skin) from four watermelon plants were combined and subjected to viral RNA preparation using Accuprep Viral RNA Extraction kit (Bioneer, Korea). In 2017, fruit samples (flesh, rind, and skin) from four symptomatic watermelon plants collected from Mitzpe-Shalem were pooled and subjected to viral RNA extraction using Accuprep Viral RNA Extraction kit (Bioneer, Korea). RNA from each extraction method was used for library construction for NGS analysis.

NGS using Illumina HiSeq and MiSeq platforms. Total RNA preparation, subjected to ribosomal RNA depletion, was used for library construction using ScriptSeq Complete kit (Plant Leaf, Illumina, San Diego, CA). Viral RNA preparation was used for library construction using TruSeq RNA Library Prep kit v2 (Illumina) according to manufacturer's protocol. The libraries were sequenced using Illumina Hiseq 2500 (50 cycles) (Technion Genome Center, Israel).

The enriched sRNA preparation was subjected to TruSeq Small RNA Sample Preparation kit (Illumina) for miRNA library construction as described previously (Sela et al. 2012). Library fragment size and quality were analyzed using the Agilent 2100 Bioanalyzer (Agilent Technologies). Size selection of the complete library was performed using E-Gel EX 4\% agarose gels (Invitrogen/ Life Technologies). The library was sequenced using the Illumina MiSeq Sequencer (50 cycles) (Volcani Center, Israel). In general, nine libraries were run per lane on the Illumina Hiseq platform, while eight libraries were run per lane on the Illumina Miseq platform.

Diagnosis of the viruses comprising the viromes by PCR or RT-PCR amplification. For the diagnosis of the viruses obtained 
by the NGS analysis and for application of the virome results for field diagnosis, specific primers were used (Table 1). Viral RNA extracted from symptomatic fruits (flesh, rind, and skin) and leaves using Accuprep Viral RNA Extraction kit (Bioneer, Korea) served for cDNA synthesis using the Maxima Reverse transcription cDNA kit (Thermo Fisher Scientific) with specific reverse primers designed for the viral sequences found by NGS analysis. The cDNA served as a template for PCR (two steps) using the specific primers (Table 1). DNA extracted from the same symptomatic samples using Dellaporta DNA extraction method (Dellaporta et al. 1983) was also subjected to PCR with the appropriate primers (Table 1). The obtained amplicons were sequenced using Sanger sequencing to confirm the authenticity of each genome segment using Basic Local Alignment Search Tool (BLAST) search algorithms against the National Center for Biotechnology Information (NCBI) GenBank (https://blast.ncbi.nlm.nih.gov/Blast.cgi).

Sequence analysis. Small RNA. Quality control of the obtained reads was performed by removing the $3^{\prime}$ adaptor from the raw reads using sRNA WORKBENCH (Stocks et al. 2012). The adaptor and low-quality reads were removed from the sRNA fastq raw reads using the 'The UEA small RNA Workbench' software version 3.2 (http://srna-workbench.cmp.uea.ac.uk/) (Stocks et al. 2012). Only sequences with at least $8 \mathrm{bp}$ matching the adaptor without mismatches were considered for further analysis. Following the adaptor removal, the sequences were filtered by length and those between 16 and 35 bp were kept (Fig. 1). The clean sequences were searched for viruses with the VirusDetect software version 1.7 using the plant virus database with default parameters. Virusdetect 1.7 uses both de-novo assembly and mapping to known virus references to create contigs. As default it uses the velvet assembler (Zerbino and Birney 2008) and bwa software (Li and Durbin 2009) for alignment (Zheng et al. 2017).

Total and viral RNA. The raw RNAseq, fastq single-end raw reads were subjected to quality filtering using the software Trimmomatic version 0.32 with the parameters "ILLUMINACLIP: TruSeq3-SE:2:30:10 LEADING:3 TRAILING:3 SLIDINGWINDOW:

\begin{tabular}{llc} 
& \multicolumn{2}{c}{ TABLE 2 } \\
& RNASeq library quality \\
\hline Library & $\begin{array}{c}\text { Number of } \\
\text { raw reads }^{\text {a }}\end{array}$ & $\begin{array}{c}\text { Number of reads after filtering } \\
\text { out low quality sequences }\end{array}$ \\
\hline $\begin{array}{l}\text { Kalia 2016 } \\
\text { Total RNA } \\
\text { extraction }\end{array}$ & $39,202,212$ & $37,218,956(94.94 \%)$ \\
\hline $\begin{array}{l}\text { Kalia 2016 viral } \\
\text { RNA extraction }\end{array}$ & $36,941,220$ & $30,955,805(83.80 \%)$ \\
\hline $\begin{array}{l}\text { Mitzpe-Shalem } \\
\text { 2017 viral RNA } \\
\text { extraction }\end{array}$ & $22,676,030$ & $22,199,756(97.90 \%)$ \\
\hline
\end{tabular}

a Total reads for each library.
A

Total SRNA raw sequences

】

Sequences after $3^{\prime}$ adaptor removal

】

Sequences after length range filtering 16-35 (nt.)

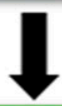

Length sequence distributions

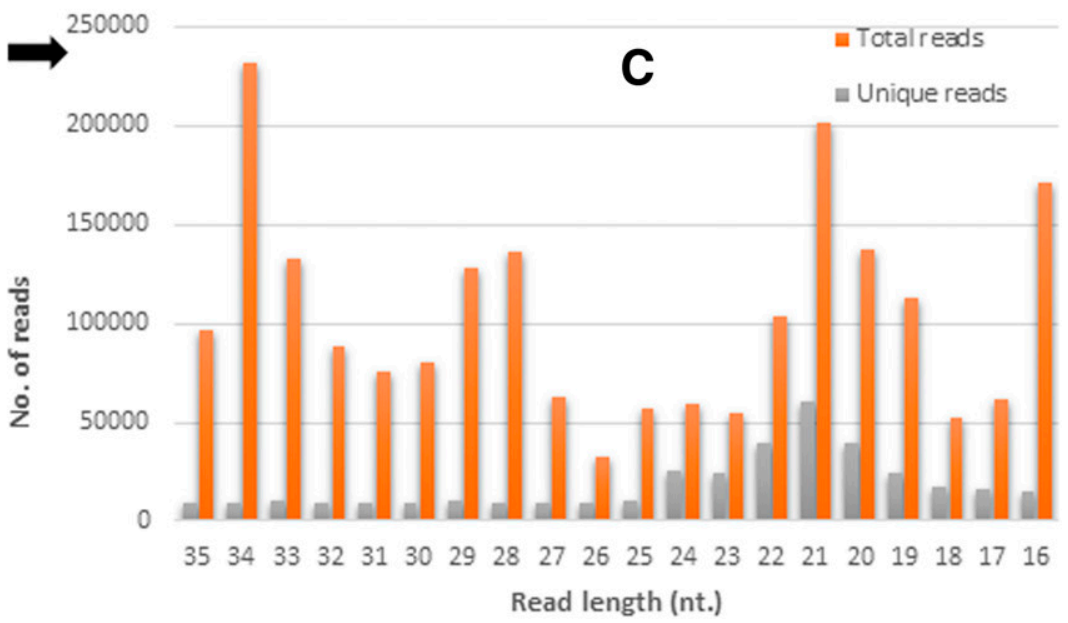

Fig. 1. Small RNA library quality of obtained reads. A, Bioinformatics analysis workflow. B, Library quality. C, Read distribution. 
TABLE 3

Viromes of watermelons from Eastern Israel ${ }^{\mathrm{a}}$

\begin{tabular}{|c|c|c|c|c|c|c|c|c|c|}
\hline Reference genome ${ }^{b}$ & $\begin{array}{l}\text { Complete } \\
\text { genome (nt) }\end{array}$ & \multicolumn{4}{|c|}{ Kalia 2016} & \multicolumn{4}{|c|}{ Mitzpe-Shalem 2017} \\
\hline $\begin{array}{l}\text { Cucurbit chlorotic yellows } \\
\text { virus (CCYV), RNA } 2\end{array}$ & 8,041 & $4,466(55.5)$ & 60 & 3.3 & 99.54 & 7,503 (93\%) & 9 & 21.8 & 99.79 \\
\hline $\begin{array}{l}\text { Cucurbit yellow stunting } \\
\text { disorder virus (CYSDV), } \\
\text { RNA2 AY242078 }\end{array}$ & 7,976 & $7,676(96.2)$ & 20 & 12.1 & 99.73 & ND & ND & ND & ND \\
\hline $\begin{array}{l}\text { Cucumber vein } \\
\text { yellowing virus } \\
\text { (CVYV) }\end{array}$ & 9,751 & ND & ND & ND & ND & 7,417 (76.1) & 31 & 231.3 & 95.44 \\
\hline $\begin{array}{l}\text { Squash leaf curl virus } \\
\text { (SLCV), DNA-A }\end{array}$ & 2,667 & 2,664 (99.9) & 2 & 48.1 & 97.53 & ND & ND & ND & ND \\
\hline $\begin{array}{l}\text { Squash leaf curl virus } \\
\text { (SLCV), DNA-B }\end{array}$ & 2,624 & 2,579 (98.3) & 5 & 42.8 & 96.52 & ND & ND & ND & ND \\
\hline \multicolumn{10}{|c|}{$\begin{array}{l}\text { An output taken from VirusDetect software. ND, not detected. } \\
\text { GenBank reference sequence accession number to which significant similarity was found with contigs assembled from the sample: (CCYV RNA1, } \\
\text { AB523788); (CCYV RNA2, AB523789); (CYSDV RNA1, EF547827); (CYSDV RNA2, AY242078); (SqVYV, KT721735); (SLCV DNA-A, KJ624994); } \\
\text { and (SLCV DNA-B, KJ579954). } \\
\text { c Percentage of the GenBank reference sequence that is covered by alignment of contigs assembled from the sample. } \\
\text { d Number of contigs, assembled from the sample, that can be aligned to the reference sequence. } \\
\text { e The average total number of times each nucleotide of the reference sequence is covered by sequences identified in the sample. } \\
\text { The average percentage of nucleotide identity to the GenBank reference sequence of all contigs aligned to that sequence. }\end{array}$} \\
\hline
\end{tabular}

TABLE 4

Comparison between three methods of library construction ${ }^{a}$

\begin{tabular}{|c|c|c|c|c|c|c|c|c|c|}
\hline \multirow[b]{2}{*}{ Reference genome ${ }^{b}$} & \multicolumn{3}{|c|}{ sRNA } & \multicolumn{3}{|c|}{ Total RNA } & \multicolumn{3}{|c|}{ Viral RNA } \\
\hline & Coverage $^{c}(\%)$ & Depth $^{d}$ & Identity ${ }^{\mathrm{e}}(\%)$ & Coverage (\%) & Depth & Identity (\%) & Coverage (\%) & Depth & Identity (\%) \\
\hline $\begin{array}{c}\text { Cucurbit chlorotic yellows } \\
\text { virus (CCYV), RNA } 1\end{array}$ & 6,904 (80.2) & 5.0 & 99.55 & $4,527(52.6)$ & 1.6 & 99.6 & 8,029 (93.28) & 4.5 & 99.63 \\
\hline $\begin{array}{c}\text { Cucurbit chlorotic yellows } \\
\text { virus (CCYV), RNA } 2\end{array}$ & $4,466(55.5)$ & 3.3 & 99.54 & 4,173 (51.9) & 1.5 & 99.7 & $7,503(93)$ & 6.6 & 99.79 \\
\hline $\begin{array}{l}\text { Cucurbit yellow stunting disorder } \\
\text { virus (CYSDV), RNA1 }\end{array}$ & $8,710(95.4)$ & 9.9 & 99.34 & $8,588(94.1)$ & 27.6 & 99.43 & $9,054(99.2)$ & 35.7 & 99.45 \\
\hline $\begin{array}{l}\text { Cucurbit yellow stunting disorder } \\
\text { virus (CYSDV), RNA2 }\end{array}$ & 7,676 (96.2) & 12.1 & 99.73 & $7,303(91.6)$ & 17.1 & 99.73 & $7,898(99)$ & 28 & 99.84 \\
\hline $\begin{array}{l}\text { Squash vein yellowing } \\
\text { virus (SqVYV) }\end{array}$ & $9,798(99.7)$ & 64.2 & 99.49 & 9,723 (98.9) & 448.3 & 99.59 & $9,779(99.5)$ & 513 & 99.46 \\
\hline $\begin{array}{l}\text { Squash leaf curl virus } \\
\text { (SLCV), DNA-A }\end{array}$ & 2,664 (99.9) & 48.1 & 97.53 & $2,667(100)$ & 94.7 & 99.7 & 2,204 (82.67) & 3.2 & 98.41 \\
\hline
\end{tabular}

a Symptomatic watermelon fruits from Kalia 2016 subjected to three different RNA extraction methods.

b Assembled from the sample: (CCYV RNA1, AB523788); (CCYV RNA2, AB523789); (CYSDV RNA1, EF547827); (CYSDV RNA2, AY242078); (SqVYV, KT721735); (SLCV DNA-A, KJ624994); and (SLCV DNA-B, KJ579954).

c Percentage of the GenBank reference sequence that is covered by alignment of contigs assembled from the sample.

d The average total number of times each nucleotide of the reference sequence is covered by sequences identified in the sample.

e The average percentage of nucleotide identity to the GenBank reference sequence of all contigs aligned to that sequence. 
4:15 MINLEN:36" (Table 2). Clean reads were then searched for viruses with the VirusDetect software version 1.7 using the plant virus database with default parameters of the software pipeline (Zheng et al. 2017). The assembly used by VirusDetect software involved a pipeline combining de novo assembly with mapping to references of plant viruses from GenBank using velvet (Zerbino and Birney 2008) and bwa (Li and Durbin 2009) for mapping reads. Table 3 summarizes the VirusDetect parameters of the contigs assembled for every virus. In the depth analysis, VirusDetect calculates how much of each contig is covered by the reference virus genome.

Calculating depth in every nucleotide position of CCYV-IL isolate. To calculate depth and coverage of a whole virus genome derived from a sRNA library or RNAseq library of the CCYV isolate (accession numbers MH477611 and MH477612), bowtie2 (Langmead and Salzberg 2012) was used. The reference was the obtained from a viral full genome sequence determined by both assembly and PCR validations. Then SAMtools ( $\mathrm{Li}$ et al.
2009) was used for depth calculations using default parameters of SAMtools software.

\section{RESULTS}

Watermelon virome as a basis for accurate field diagnosis. Watermelon viromes were analyzed in two adjacent open fields: Kalia and Mitzpe-Shalem in 2016 and 2017, respectively. Viruses that comprised the virome of watermelon fruits from Kalia differed from those that comprised the virome of fruits from Mitzpe-Shalem (Table 3). Importantly, watermelon fruits brought from Kalia were subjected to three RNA extraction methods. NGS analysis of all three RNA preparations: sRNA, total RNA and viral RNA revealed the occurrence of the same viruses in the symptomatic watermelons (Table 4). Watermelon fruits brought from Mitzpe-Shalem were subjected to NGS analysis of extracted viral RNA. In Kalia in 2016, the watermelon field did not seem to have any distinctive characteristics, although the fruits showed severe disease symptoms

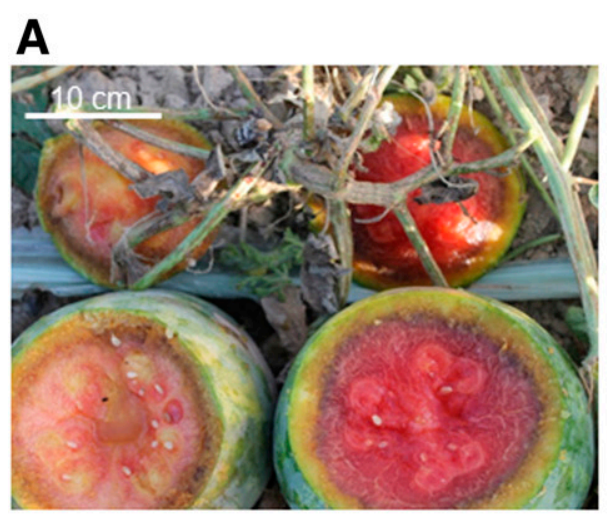

D

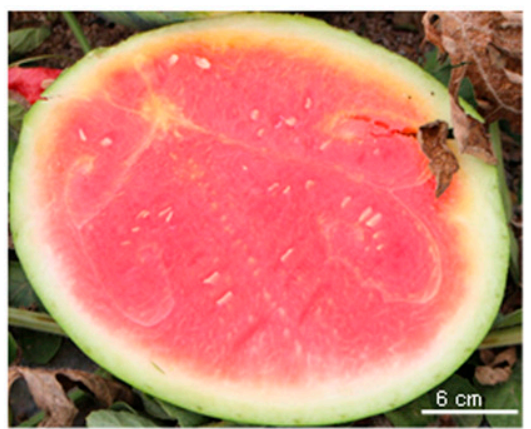

G

$\mathbf{F}$

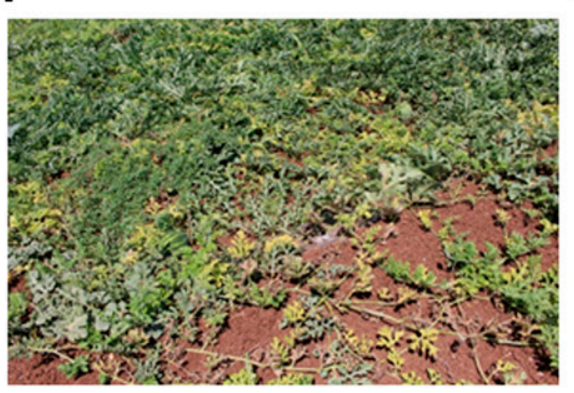

B

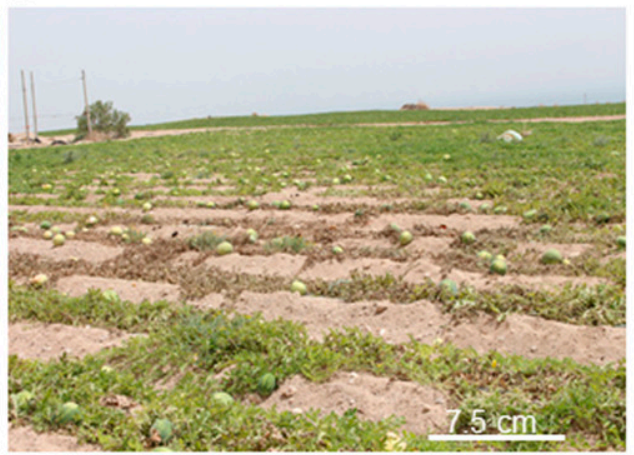

E
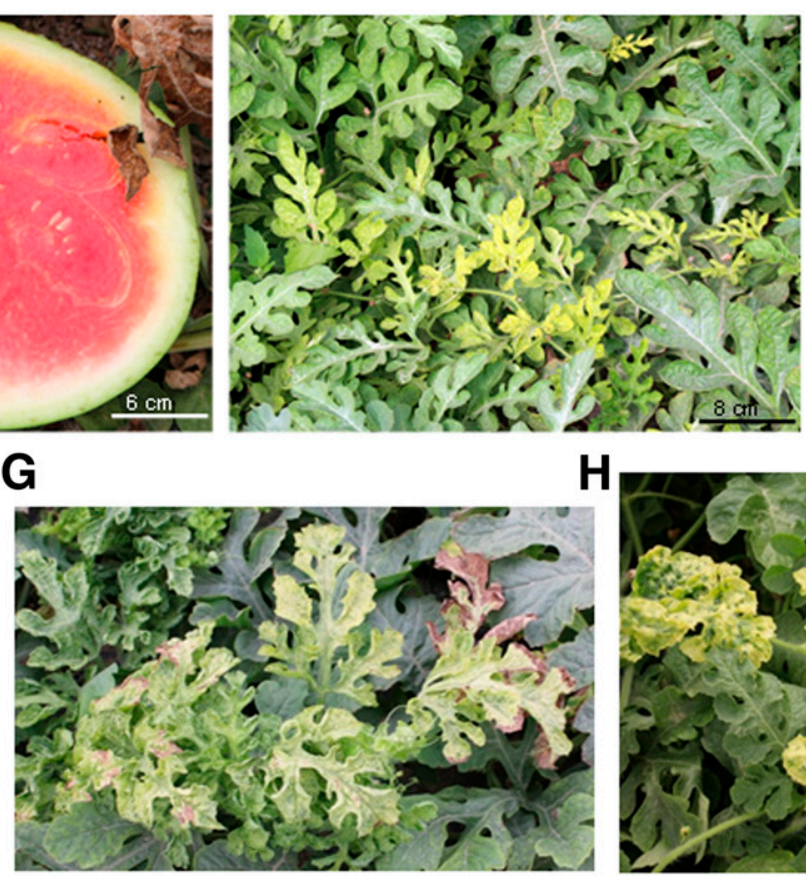

C

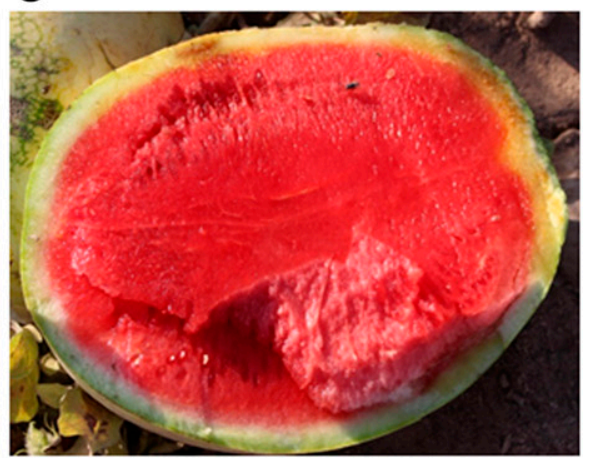

$\mathrm{H}$

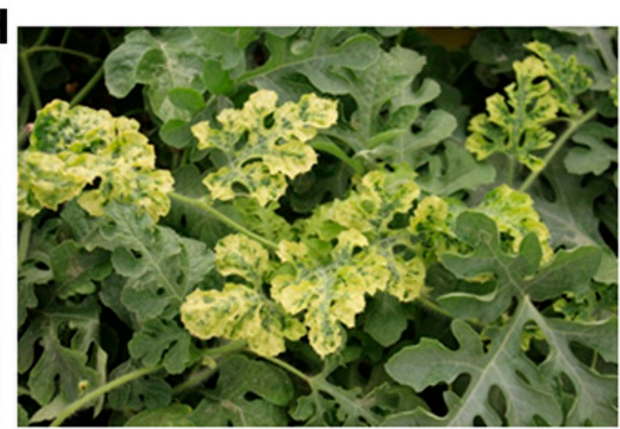

Fig. 2. Symptomatic watermelon plants. A, Kalia watermelons in 2016 showing rotten fruit flesh with brown spotted flesh, rind, and skin. B, Mitzpe-Shalem field in 2017 showing watermelon vine decline (WVD). C, Mitzpe-Shalem watermelon fruit in 2017 showing necrotic brown rind. D, Arava Valley, Cucurbit chlorotic yellows virus (CCYV)-infected watermelon fruit showing yellowing rind and flesh. E, Arava Valley, chlorotic CCYV-infected watermelon leaves. F, Ein Harod, early symptoms of necrosis and leaf yellowing associated with WVD. G, Ein Harod, leaf curling with brown lesions. H, Ein Harod, chlorotic mottling of apical leaves and leaf curling. 
(Fig. 2A). The fruit flesh was severely rotted with brown streaks in the rind and skin. NGS analysis of sRNA prepared from the fruits (flesh, rind, and skin) showed the presence of viruses of three different genera: the begomovirus SLCV, the criniviruses Cucurbit yellow stunting disorder virus (CYSDV) and CCYV, and the ipomovirus SqVYV (Table 3). In Mitzpe-Shalem in 2017, the watermelon field showed the characteristic watermelon vine decline (WVD) that occurred in plants infected by the ipomovirus SqVYV (Adkins et al. 2007, 2008; Reingold et al. 2016) (Fig. 2B). Analysis of the raw RNA reads prepared from the fruits (flesh, rind and skin)
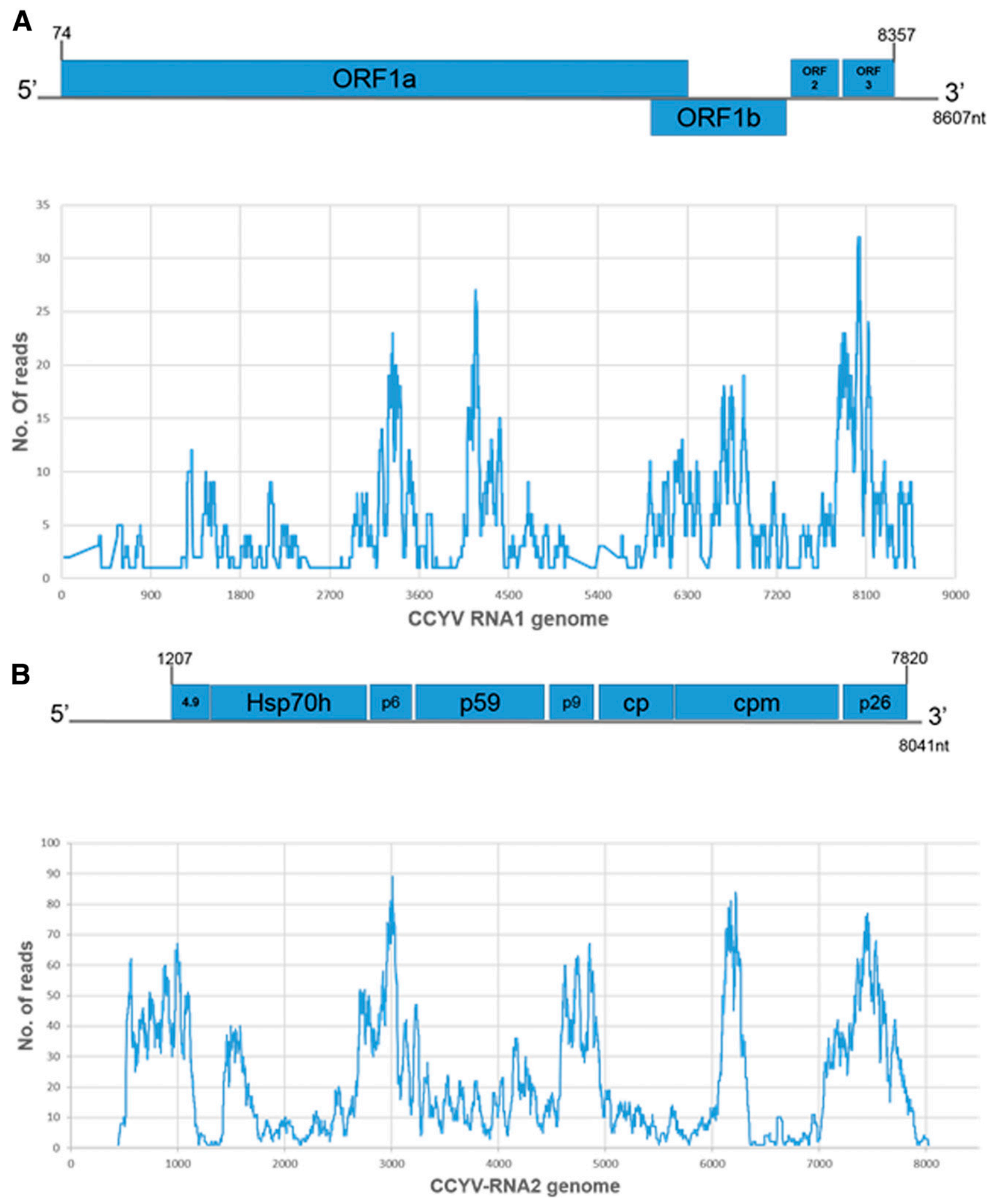

Fig. 3. Obtained reads and coverage of the Israeli isolate of Cucurbit chlorotic yellows virus (CCYV-IL). A, A scheme of genome organization of CCYV-IL and distribution of the obtained reads along the CCYV-IL RNA1 genome. B, A scheme of genome organization of CCYV-IL and distribution of the obtained reads along the CCYV-IL RNA2 genome. CP, coat protein; and CPM, minor cp. 
revealed that, indeed, SqVYV was one of two ipomoviruses that infected the plants. The symptomatic fruits showed brown rotten spots on flesh, rind, and skin (Fig. 2C). In Mitzpe-Shalem, in addition to $\mathrm{SqVYV}$, the ipomovirus Cucumber vein yellowing virus (CVYV) and the crinivirus CCYV were detected. All the detected viruses were transmitted by the whitefly $B$. tabaci. Importantly, CCYV, not described previously in Israel, was identified in both locations (Table 3). To the best of our knowledge, this is the first report of CCYV in Israel. Interestingly, a single infection of watermelon plants by CCYV that caused characteristic yellowing fruit flesh and chlorotic leaves was identified in watermelon fruit and leaf samples in 2018 from the Arava Valley in Southern Israel (Fig. 2D and E). These samples detected negatively by PCR for SLCV and WmCSV; and by RT-PCR for CYSDV, CVYV, and SqVYV. Sequencing of the bipartite positive-sense RNA genome of CCYVIL was done by combining NGS analysis of two RNA preparations: sRNA preparation obtained from Kalia 2016 watermelon samples and viral RNA preparation obtained from Mitzpe-Shalem 2017 watermelon samples. NGS analysis of CCYV-IL identified in the viral RNA prepared from Mitzpe-Shalem 2017 watermelon samples is depicted in Figure 3. Genome length coverage of RNA1 was from position $305^{\prime} \mathrm{UTR}$ (nt) to position 8,591 (nt) 3'UTR and of RNA2 was from position 441 (nt) $5^{\prime}$ UTR to position 8,029 (nt) $3^{\prime}$ UTR as illustrated in the Figure 3.

Temporal and spatial effects on viruses infecting watermelons. A temporal effect on the occurrence of viruses infecting watermelons was studied by PCR analysis of watermelon plants collected from Kalia in the years 2017 and 2018 (Table 5). Apparently CVYV, absent in the virome analysis of watermelon fruits brought from Kalia in 2016, was detected in watermelon fruits collected from Kalia in both 2017 and 2018 (Tables 3 and 5). No temporal effect was observed regarding the occurrence of SqVYV, CYSDV, and CCYV that comprised the virome of watermelon fruits brought from Kalia in 2016 and were detected, using RT-PCR analysis, in watermelon fruits brought from Kalia in 2017 and 2018 (Tables 3 and 5). Similarly, no temporal effect was observed on the occurrence of SLCV. SLCV was detected by NGS analysis of watermelon fruits from Kalia in 2016 and by PCR analysis of watermelon fruits from Kalia in 2018, showing $12.5 \%$ infectivity ratio (number of samples $=24$ ). A spatial effect was studied by comparing watermelon plants collected from Northern Israel (Eden farm and Ein-Harod), to plants collected from Kalia and MitzpeShalem. In 2017, SqVYV was detected in fruits from both Kalia (using RT-PCR analysis) and Mitzpe-Shalem (using NGS analysis), but was absent in RT-PCR analysis of fruits collected from Eden farm (Tables 3, 5, and 6). A spatial effect was also observed regarding the occurrence of the begomovirus WmCSV, that showed a $100 \%$ infectivity ratio $(n=10)$ by PCR analysis of leaves brought from Ein Harod in 2018; WmCSV was absent in watermelon fruits from Kalia in the same year (Tables 5 and 6). Severe symptoms of chlorotic mottling and apical leaf curling were observed in watermelon plants brought from Ein Harod (Fig. $2 \mathrm{~F}$ to H). In the same samples from Ein Harod, the begomovirus SLCV showed a $100 \%$ infectivity ratio $(n=10)$ as well. Importantly, the crinivirus CCYV, which was not previously detected in Israel, occurred in watermelon plants (fruit, flesh, skin, and leaves) collected from all sites for the years 2016 and 2018.

Open field viruliferous whiteflies transmit the viruses infecting watermelons. In the center of the open field in Kalia in 2018, three rows of watermelon plants were covered with an antiinsect net preventing whitefly entry (Fig. 4). The ipomoviruses SqVYV and CVYV were detected by RT-PCR in the fruits (flesh, rind, and skin) collected from the uncovered area, as well as the criniviruses CYSDV and CCYV (Table 5). Importantly, the same viruses did not infect the watermelons collected from the net covered area.

\section{DISCUSSION}

Environmental effects on a virome may be crucial for the development of symptomatic plants. To isolate the effects of changing environmental surroundings on the diversity of the viruses comprising a watermelon virome, we analyzed the viromes of watermelons grown in two separate locations: Kalia and Mitzpe-Shalem. In the study of watermelon fruits brought from Kalia in 2016, we conducted NGS analysis of three different RNA preparations: sRNA, total RNA, and viral RNA, which produced similar results. Our results emphasized the use of viral RNA preparations, which are easy to make, are less time consuming, and require small samples of starting material, for virome analysis. These results strengthen the validity of the NGS analysis conducted on viral RNA extracts prepared from symptomatic watermelon fruits brought from Mitzpe-Shalem in 2017. We found differences in the viruses comprising the viromes of the symptomatic watermelons from the two locations. The differences between the viromes might have been the result of temporal changes between the years 2016 and 2017. We therefore analyzed the viruses infecting watermelon fruits brought from Kalia in 2017 and 2018 as well, using PCR analysis. Indeed, RT-PCR analysis showed that the ipomovirus CVYV infected the watermelon fruits brought from Kalia in 2017, as was observed in the NGS analysis of watermelon fruits collected from the near-by Mitzpe-Shalem in the same year. Unlike CVYV, there is no temporal effect but only a spatial effect on the occurrence of the crinivirus CYSDV. CYSDV was detected specifically in the virome

TABLE 5

Temporal and net effect on viruses infecting watermelons in open field Kalia

\begin{tabular}{lccc}
\hline & \multicolumn{3}{c}{ Infectivity ratios determined by RT-PCR } \\
\cline { 2 - 4 } Virus & $\begin{array}{c}2017(\%), \\
(n=30)\end{array}$ & $\begin{array}{c}2018(\%), \\
(n=24)\end{array}$ & $\begin{array}{c}\text { 2018, under } \\
\text { net }(\%),(n=24)\end{array}$ \\
\hline SqVYV & 70.0 & 29.2 & 0.0 \\
\hline CVYV & 93.3 & 87.5 & 0.0 \\
\hline CYSDV & 100.0 & 79.2 & 0.0 \\
\hline CCYV & 83.3 & 62.5 & 0.0 \\
\hline
\end{tabular}

a SqVYV, Squash vein yellowing virus; CVYV, Cucumber vein yellowing virus; CYSDV, Cucurbit yellow stunting disorder virus; and CCYV, Cucurbit chlorotic yellows virus; and $n$, number of samples.

\begin{tabular}{lcc} 
& $\begin{array}{c}\text { TABLE } 6 \\
\text { Viruses infecting watermelons in Northern Israel }\end{array}$ \\
\hline & \begin{tabular}{c} 
Infectivity ratios determined by RT-PCR \\
\cline { 2 - 3 } Virus
\end{tabular} & $\begin{array}{c}\text { Eden farm, 2017 } \\
(\%, n=39)^{\mathrm{b}} \\
(\%, n=10)^{\mathrm{c}}\end{array}$ \\
\hline SqVYV & 0.0 & 10.0 \\
\hline CVYV & 89.7 & 80.0 \\
\hline CYSDV & 46.2 & 50.0 \\
\hline CCYV & 46.2 & 10.0 \\
\hline a SqVYV, Squash vein yellowing virus; CVYV, Cucumber vein \\
yellowing virus; CYSDV, Cucurbit yellow stunting disorder virus; \\
bCYV, Cucurbit chlorotic yellows virus; and $n$, number of samples. \\
b Fruit samples. \\
c Leaf samples.
\end{tabular}


of watermelon fruits from Kalia in 2016 and was also detected in watermelon fruits brought from Kalia in 2017, using RT-PCR analysis. However, CYSDV was not detected in the virome of watermelon fruits brought from Mitzpe-Shalem in 2017. A spatial effect was also observed regarding the occurrence of the ipomovirus SqVYV that was detected in watermelon fruits from Kalia and from the nearby Mitzpe-Shalem in 2017, but was not detected in watermelon fruits brought from the Northern Eden farm in the same year. Similarly, a spatial effect was observed regarding the occurrence of the begomovirus WmCSV. The severe symptoms observed in watermelon leaves brought from Ein Harod in 2018 could not be attributed to the infecting viruses CVYV or CYSDV, which had infectivity ratios of 80 and $50 \%$, respectively. CVYV causes yellowing of leaf veins (Louro et al. 2004) and CYSDV causes interveinal chlorosis of older leaves (Tzanetakis et al. 2013). Since the watermelon leaves from Ein Harod showed severe chlorotic mottling and curling of apical leaves which resembled WmCSV symptoms, we analyzed the leaves for the occurrence of WmCSV (Ali-Shtayeh et al. 2014). We also analyzed the leaves for the occurrence of SLCV, that is known to synergize with WmCSV upon double infection of Cucumis melo plants (Sufrin-Ringwald and Lapidot 2011). Both WmCSV and SLCV showed 100\% infectivity ratios by PCR analysis. In watermelon fruits brought from Kalia however, PCR analysis showed that WmCSV was absent in the same year and only SLCV was detected.

Importantly, in NGS analysis of watermelon fruits brought from Kalia in 2016, we found the crinivirus CCYV, which was not previously identified in Israel. The presence of CCYV in the surrounding countries Lebanon, Egypt, Iran, and Greece has been reported (Abrahamian et al. 2012; Amer 2015; Keshavarz et al. 2014; Orfanidou et al. 2014). In the bipartite positive-sense RNA genome of CCYV, RNA1 encodes proteins associated with the replication process. The CCYV RNA2 encodes several proteins, including the structural coat protein $(\mathrm{CP})$, the minor $\mathrm{CP}$ and a homolog of the $70 \mathrm{kDa}$ heat shock protein, that have distinctive characteristics for each crinivirus species. The occurrence of CCYV infection in Israel was independent of temporal or spatial changes. Interestingly, members of the genus Crinivirus are known to reduce fruit yield and cause crop damage synergistically when coinfected with viruses of the genera Begomovirus and Ipomovirus (Cuellar et al. 2015; Gil-Salas et al. 2012). Such a synergism might have caused the severe symptoms on the watermelons from Kalia in 2016. In addition, the fact that CCYV was present in all the sampled areas might implicate the virus in all the severe manifestations of the watermelon disease symptoms by suppression of the RNA silencing mechanism (Landeo-Ríos et al. 2017).

As mentioned above, CCYV is preferentially transmitted by the MED biotype of the whitefly Bemisia tabaci (Lu et al. 2017). In many fields across Israel in the years 2009 to 2012, a shift in biotype distribution had occurred, favoring MEAM1 over MED (Horowitz and Ishaaya 2014). The new occurrence of CCYV in Israel might infer that a new dynamic in $B$. tabaci biotypes had occurred in the country, as had recently observed in other countries (Chu et al. 2014; Lemmetty and Vänninen 2014; McKenzie and Osborne 2017; Pan et al. 2011; Tsueda and Tsuchida 2011). Since a mutualistic relationship occurs between the vector and CCYV, the

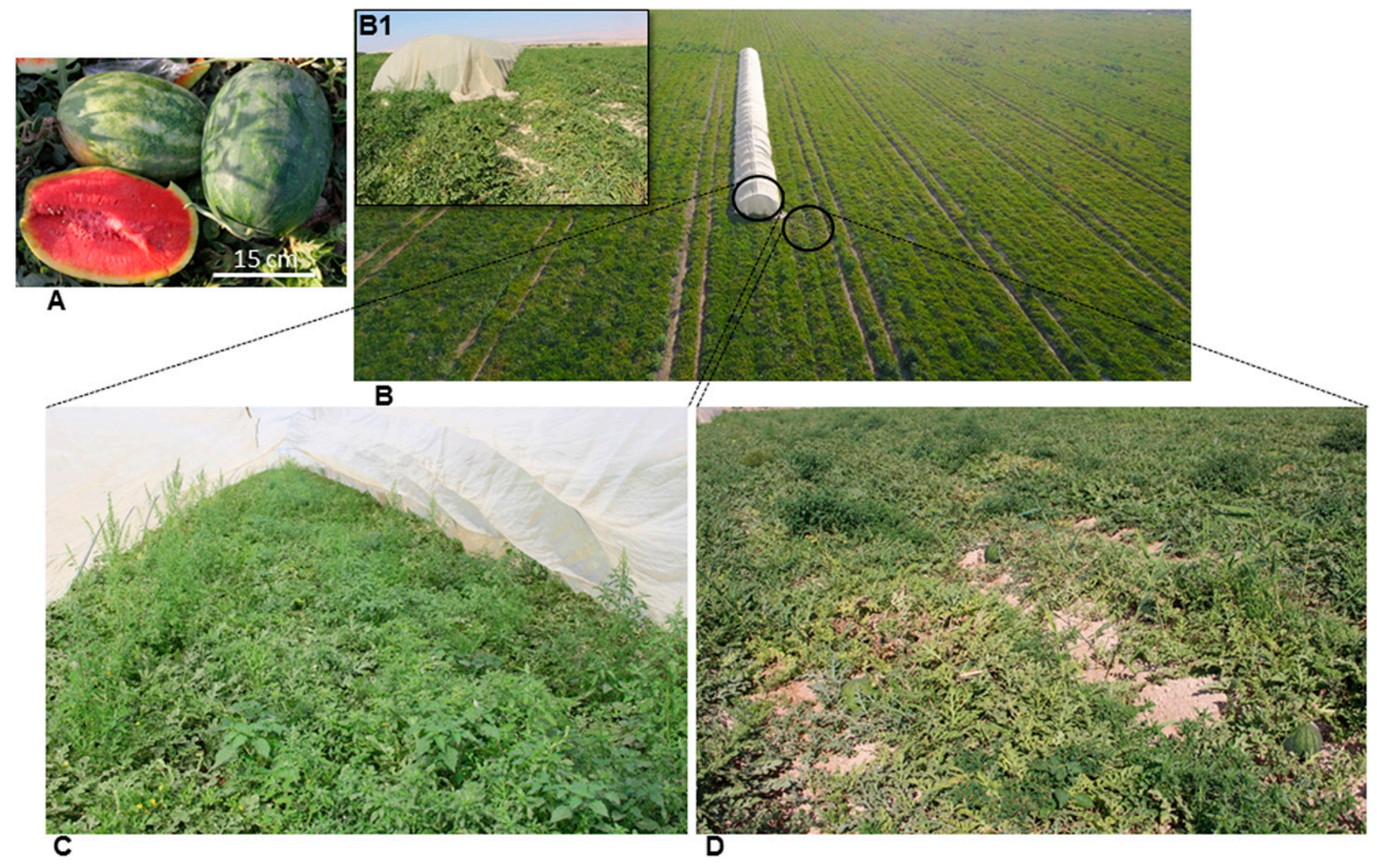

Fig. 4. The effect of an anti-insect net 50 mesh on whitefly infestation and virus transmission in watermelon field in Kalia in 2018. A, Watermelons from the open field showing brown rotten spots on the rind. B, A walk-in tunnel of an anti-insect net 50 mesh, $100 \mathrm{~m}$ long and $6 \mathrm{~m}$ wide, placed in the middle of the open field. B1, A close-up of the net and the field adjacent to it. C, Asymptomatic watermelon plants grown inside the net. D, Dried infected watermelon plants grown outside the net. 
virus might have induced a relative increase in the MED population (Lu et al. 2017; Stout et al. 2006). Changes in whitefly populations and time of appearance might occur due to climate change as well (Canto et al. 2009). Changes in the geographical distribution of the whitefly vector might also cause increased occurrence of synergism between viruses that have a newly overlapping presence (Canto et al. 2009).

This study emphasizes the importance of the viral diseases caused by viruliferous whiteflies. In addition to climate changes, weeds and cultivated crops play an important role as reservoirs of the whiteflies that maintain the vector between seasons (Wisler and Norris 2005). Interestingly, plants that repel whiteflies, such as celery (Tu and Qin 2017) and wild tomatoes (Bleeker et al. 2009), may be grown adjacent to a cultivated crop and reduce the infestation and overwintering of the whiteflies. Implementation of this approach might improve the efficiency of pest management and control of whiteflytransmitted viruses.

\section{ACKNOWLEDGMENTS}

Contribution from the Agricultural Research Organization, The Volcani Center, Bet Dagan, Israel, number 586/18. We thank V. Gaba for editing the manuscript.

\section{LITERATURE CITED}

Abrahamian, P., Sobh, H., and Abou-Jawdah, Y. 2012. First report of Cucurbit chlorotic yellows virus on cucumber in Lebanon. Plant Dis. 96:1704.

Abrahamian, P. E., and Abou-Jawdah, Y. 2014. Whitefly-transmitted criniviruses of cucurbits: Current status and future prospects. VirusDisease 25:26-38.

Abudy, A., Sufrin-Ringwald, T., Dayan-Glick, C., Guenoune-Gelbart, D. Livneh, O., Zaccai, M., and Lapidot, M. 2010. Watermelon chlorotic stunt and Squash leaf curl begomoviruses-New threats to cucurbit crops in the Middle East. Isr. J. Plant Sci. 58:33-42.

Adkins, S., Webb, S. E., Achor, D., Roberts, P. D., and Baker, C. A. 2007. Identification and characterization of a novel whitefly-transmitted member of the family Potyviridae isolated from cucurbits in Florida. Phytopathology 97: 145-154.

Adkins, S., Webb, S. E., Baker, C. A., and Kousik, C. S. 2008. Squash vein yellowing virus detection using nested polymerase chain reaction demonstrates that the cucurbit weed Momordica charantia is a reservoir host. Plant Dis. 92:1119-1123.

Ali-Shtayeh, M. S., Jamous, R. M., Mallah, O. B., and Abu-Zeitoun, S. Y. 2014. Molecular characterization of Watermelon chlorotic stunt virus (WmCSV) from Palestine. Viruses 6:2444-2462.

Amer, M. A. 2015. Serological and molecular characterization of Cucurbit chlorotic yellows virus affecting cucumber plants in Egypt. Int. J. Virol. 11: $1-11$.

Baulcombe, D. 1999. Viruses and gene silencing in plants. Pages 189-201 in: 100 Years of Virology. Springer.

Bleeker, P. M., Diergaarde, P. J., Ament, K., Guerra, J., Weidner, M., Schütz, S., de Both, M. T., Haring, M. A., and Schuurink, R. C. 2009. The role of specific tomato volatiles in tomato-whitefly interaction. Plant Physiol. 151:925-935.

Canto, T., Aranda, M. A., and Fereres, A. 2009. Climate change effects on physiology and population processes of hosts and vectors that influence the spread of hemipteran-borne plant viruses. Glob. Change Biol. 15:1884-1894.

Chu, D., Guo, D., Tao, Y., Jiang, D., Li, J., and Zhang, Y. 2014. Evidence for rapid spatiotemporal changes in genetic structure of an alien whitefly during initial invasion. Sci. Rep. 4:4396.

Cuellar, W. J., Galvez, M., Fuentes, S., Tugume, J., and Kreuze, J. 2015. Synergistic interactions of begomoviruses with Sweet potato chlorotic stunt virus (genus Crinivirus) in sweet potato (Ipomoea batatas L.). Mol. Plant Pathol. 16:459-471.

Dellaporta, S. L., Wood, J., and Hicks, J. B. 1983. A plant DNA minipreparation: Version II. Plant Mol. Biol. Report. 1:19-21.

Dombrovsky, A., Reingold, V., and Antignus, Y. 2014. Ipomovirus-an atypical genus in the family Potyviridae transmitted by whiteflies. Pest Manag. Sci. 70: 1553-1567.
Ghanim, M. 2014. A review of the mechanisms and components that determine the transmission efficiency of Tomato yellow leaf curl virus (Geminiviridae; Begomovirus) by its whitefly vector. Virus Res. 186:47-54.

Gil-Salas, F., Peters, J., Boonham, N., Cuadrado, I., and Janssen, D. 2012. Coinfection with Cucumber vein yellowing virus and Cucurbit yellow stunting disorder virus leading to synergism in cucumber. Plant Pathol. 61:468-478.

Gilbertson, R. L., Batuman, O., Webster, C. G., and Adkins, S. 2015. Role of the insect supervectors Bemisia tabaci and Frankliniella occidentalis in the emergence and global spread of plant viruses. Annu. Rev. Virol. 2:67-93.

Hadjistylli, M., Roderick, G. K., and Brown, J. K. 2016. Global population structure of a worldwide pest and virus vector: Genetic diversity and population history of the Bemisia tabaci sibling species group. PLoS One 11:e0165105.

Harpaz, I., and Cohen, S. 1965. Semipersistent relationship between Cucumber vein yellowing virus (CVYV) and its vector, the tobacco whitefly (Bemisia tabaci Gennadius). Phytopathology 54:240-248.

Horowitz, A. R., and Ishaaya, I. 2014. Dynamics of biotypes B and Q of the whitefly Bemisia tabaci and its impact on insecticide resistance. Pest Manag. Sci. 70:1568-1572.

Incarbone, M., and Dunoyer, P. 2013. RNA silencing and its suppression: Novel insights from in planta analyses. Trends Plant Sci. 18:382-392.

Jones, D. R. 2003. Plant viruses transmitted by whiteflies. Eur. J. Plant Pathol. 109:195-219.

Kamitani, M., Nagano, A. J., Honjo, M. N., and Kudoh, H. 2016. RNA-Seq reveals virus-virus and virus-plant interactions in nature. FEMS Microbiol. Ecol.: 92:fiw176.

Keshavarz, T., Shams-Bakhsh, M., Izadpanah, K., and Malboobi, M. A. 2014. Occurrence and genome analysis of Cucurbit chlorotic yellows virus in Iran. J. Phytopathol. 162:523-526.

Landeo-Ríos, Y., Navas-Castillo, J., Moriones, E., and Cañizares, M. C. 2017. The heterologous expression of the p22 RNA silencing suppressor of the crinivirus Tomato chlorosis virus from Tobacco rattle virus and Potato virus $X$ enhances disease severity but does not complement suppressor-defective mutant viruses. Viruses 9:358.

Langmead, B., and Salzberg, S. L. 2012. Fast gapped-read alignment with Bowtie 2. Nat. Methods 9:357-359.

Lapidot, M., Legg, J. P., Wintermantel, W. M., and Polston, J. E. 2014. Management of whitefly-transmitted viruses in open-field production systems.Adv. Virus Res. 90:147-206.

Lecoq, H., Dufour, O., Wipf-Scheibel, C., Girard, M., Cotillon, A., and Desbiez, C. 2007. First report of Cucumber vein yellowing virus in melon in France. Plant Dis. 91:909.

Lemmetty, A., and Vänninen, I. 2014. Bemisia tabaci biotype Q determined for the first time on poinsettia crops in Finland and Sweden. Annales Zoologici Fennici 51:501-506

Li, H., and Durbin, R. 2009. Fast and accurate short read alignment with Burrows-Wheeler transform. Bioinformatics 25:1754-1760.

Li, H., Handsaker, B., Wysoker, A., Fennell, T., Ruan, J., Homer, N., Marth, G., Abecasis, G., and Durbin, R. 2009. The sequence alignment/map format and SAMtools. Bioinformatics 25:2078-2079.

Louro, D., Quinot, A., Neto, E., Fernandes, J., Marian, D., Vecchiati, M., Caciagli, P., and Vaira, A. 2004. Occurrence of Cucumber vein yellowing virus in cucurbitaceous species in southern Portugal. Plant Pathol. 53:241.

Lu, S., Li, J., Wang, X., Song, D., Bai, R., Shi, Y., Gu, Q., Kuo, Y.-W., Falk, B. W., and Yan, F. 2017. A semipersistent plant virus differentially manipulates feeding behaviors of different sexes and biotypes of its whitefly vector. Viruses 9:4.

McKenzie, C. L., and Osborne, L. S. 2017. Bemisia tabaci MED (Q biotype)(Hemiptera: Aleyrodidae) in Florida is on the move to residential landscapes and may impact open-field agriculture. Fla. Entomol. 100: 481-484.

Navas-Castillo, J., Fiallo-Oliv'e, E., and S'anchez-Campos, S. 2011. Emerging virus diseases transmitted by whiteflies. Annu. Rev. Phytopathol. 49:219-248.

Orfanidou, C., Maliogka, V., and Katis, N. 2014. First report of Cucurbit chlorotic yellows virus in cucumber, melon, and watermelon in Greece. Plant Dis. 98:1446.

Pagán, I., Montes, N., Milgroom, M. G., and García-Arenal, F. 2014. Vertical transmission selects for reduced virulence in a plant virus and for increased resistance in the host. PLoS Pathog 10:e1004293.

Pakkianathan, B. C., Kontsedalov, S., Lebedev, G., Mahadav, A., Zeidan, M., Czosnek, H., and Ghanim, M. 2015. Replication of Tomato yellow leaf curl virus in its whitefly vector Bemisia tabaci. J. Virol. 89:9791-9803.

Pan, H., Chu, D., Ge, D., Wang, S., Wu, Q., Xie, W., Jiao, X., Liu, B., Yang, X., and Yang, N. 2011. Further spread of and domination by Bemisia tabaci 
(Hemiptera: Aleyrodidae) biotype Q on field crops in China. J. Econ. Entomol. 104:978-985.

Pecman, A., Kutnjak, D., Gutiérrez-Aguirre, I., Adams, I., Fox, A., Boonham, N., and Ravnikar, M. 2017. Next generation sequencing for detection and discovery of plant viruses and viroids: Comparison of two approaches. Front. Microbiol. 8:1998.

Reingold, V., Lachman, O., Sela, N., Luria, N., and Dombrovsky, A. 2016. Watermelon fruit rot disease in Israel is caused by a distinct Squash vein yellowing virus (SqVYV) strain. Plant Dis. 100:1176-1183.

Roossinck, M. J., Martin, D. P., and Roumagnac, P. 2015. Plant virus metagenomics: Advances in virus discovery. Phytopathology 105:716-727.

Rosen, R., Kanakala, S., Kliot, A., Pakkianathan, B. C., Farich, B. A., SantanaMagal, N., Elimelech, M., Kontsedalov, S., Lebedev, G., and Cilia, M. 2015. Persistent, circulative transmission of begomoviruses by whitefly vectors. Curr. Opin. Virol. 15:1-8.

Santala, J., and Valkonen, J. P. 2018. Sensitivity of small RNA-based detection of plant viruses. Front. Microbiol. 9.

Sela, N., Luria, N., and Dombrovsky, A. 2012. Genome assembly of bell pepper endornavirus from small RNA. J. Virol. 86:7721.

Stocks, M. B., Moxon, S., Mapleson, D., Woolfenden, H. C., Mohorianu, I., Folkes, L., Schwach, F., Dalmay, T., and Moulton, V. 2012. The UEA sRNA workbench: A suite of tools for analyzing and visualizing next generation sequencing microRNA and small RNA datasets. Bioinformatics 28:2059-2061.

Stout, M. J., Thaler, J. S., and Thomma, B. P. 2006. Plant-mediated interactions between pathogenic microorganisms and herbivorous arthropods. Annu. Rev. Entomol. 51:663-689.
Sufrin-Ringwald, T., and Lapidot, M. 2011. Characterization of a synergistic interaction between two cucurbit-infecting begomoviruses: Squash leaf curl virus and Watermelon chlorotic stunt virus. Phytopathology 101:281-289.

Syller, J. 2012. Facilitative and antagonistic interactions between plant viruses in mixed infections. Mol. Plant Pathol. 13:204-216.

Tsueda, H., and Tsuchida, K. 2011. Reproductive differences between Q and B whiteflies, Bemisia tabaci, on three host plants and negative interactions in mixed cohorts. Entomol. Exp. Appl. 141:197-207.

Tu, H., and Qin, Y. 2017. Repellent effects of different celery varieties in Bemisia tabaci (Hemiptera: Aleyrodidae). Biotype Q. J. Econ. Entomol. 110: 1307-1316.

Tzanetakis, I. E., Martin, R. R., and Wintermantel, W. 2013. Epidemiology of criniviruses: An emerging problem in world agriculture. Front. Microbiol. 4: 119.

Valli, A., Oliveros, J. C., Molnar, A., Baulcombe, D., and García, J. A. 2011. The specific binding to 21-nt double-stranded RNAs is crucial for the antisilencing activity of Cucumber vein yellowing virus $\mathrm{P} 1 \mathrm{~b}$ and perturbs endogenous small RNA populations. RNA 17:1148-1158.

Wisler, G. C., and Norris, R. F. 2005. Interactions between weeds and cultivated plants as related to management of plant pathogens. Weed Sci. 53:914-917.

Zerbino, D. R., and Birney, E. 2008. Velvet: Algorithms for de novo short read assembly using de Bruijn graphs. Genome Res. 18:821-829.

Zheng, Y., Gao, S., Padmanabhan, C., Li, R., Galvez, M., Gutierrez, D., Fuentes, S., Ling, K.-S., Kreuze, J., and Fei, Z. 2017. VirusDetect: An automated pipeline for efficient virus discovery using deep sequencing of small RNAs. Virol. 500:130-138. 